\title{
ASSOCIATION OF SERUM FOLLICLE STIMULATING HORMONE AND SERUM LUTEINIZING HORMONE WITH SECONDARY INFERTILITY IN OBESE FEMALES IN PAKISTAN
}

\author{
Humera Khan, Nimrah Siddique*, Rabia Akhtar Cheema** \\ District Headquarter Teaching Hospital, Sahiwal Pakistan, *CMH Institute of Medical Sciences, Bahawalpur/National University of Medical \\ Sciences (NUMS) Pakistan, **Independent Medical College, Faisalabad Pakistan
}

\begin{abstract}
Objective: To finding the association of serum follicle stimulating hormone (FSH) and luteinizing hormone (LH) with secondary infertility in obese females in Pakistan.

Study Design: Cross sectional study.

Place and Duration of Study: District head quarter Hospital Sahiwal, from Mar 2018 to May 2018.

Methodology: The study was conducted at district head quarter hospital Sahiwal after approval from Institutional Review Board of Sahiwal Medical College Sahiwal. The Data was assessed by IBM-SPSS version 24. Frequency distributions of study participants were calculated. Significance of the associations was assessed by independent sample t-test. Bivariate analysis was also done to check the effect of different factors on secondary infertility separately. The $p$-value less than 0.05 was taken as statistically significant.

Results: Mostly (43.3\%) belonged to middle class socioeconomic group. Nearly $54 \%$ were from urban residential areas. Majority belonged to (65\%) age group between 31-40 years. When we calculated the association of serum follicle stimulating hormone and serum luteinizing hormone with the secondary infertility in these study participants then it was conclusive to find out that mean levels of both follicle stimulating hormone and luteinizing hormone were quite low (12.11 \pm 1.14 and $21.97 \pm 3.74$ respectively) in patients with secondary infertility as compared to those which were not suffering from it. Association of serum follicle stimulating hormone was also found to be statistically significant with secondary infertility $(p=0.042)$.

Conclusion: Hence it is concluded that the low levels of serum follicle stimulating hormone are strongly associated with secondary infertility in obese women.
\end{abstract}

Keywords: Obese, Secondary infertility, Serum follicle stimulating hormone, Serum luteinizing hormone.

\footnotetext{
This is an Open Access article distributed under the terms of the Creative Commons Attribution License (http://creativecommons.org/licenses/by/4.0), which permits unrestricted use, distribution, and reproduction in any medium, provided the original work is properly cited.
}

\section{INTRODUCTION}

Infertility refers to conception failure by a couple and is perceived as a multifactorial syndrome in all cultures and societies. Approximately $23 \%$ couples of reproductive age group are affected in Pakistan, of whom 5\% contribute to primary infertility and $18 \%$ to secondary causes ${ }^{1}$. During this process of folliculogenesis, the oocyte undergoes a significant array of genetic, epigenetic and cytoplasmic alterations in order to achieve fertilization proficiency. This whole course of events depends on a continuous cross-talk between oocytes and granulosa cells that safeguard the coordination of all the events sequenced in

Correspondence: Dr Humera Khan, Department of Biochemistry, University of Health Sciences, Lahore Pakistan.

Received: 05 Dec 2018; revised received: 07 Jun 2019; accepted: 20 Jun 2019 the ovary under the influence of paracrine and endocrine factors, hormones and peptides ${ }^{2}$. Maintenance of ovarian reserve is dependent on extrinsic (xenobiotic and anticancer drugs) and intrinsic (endometriosis, diabetes, polycystic ovarian syndrome [PCOS] and ovarian aging) factors ${ }^{3}$.

Although Pakistan is among the currently most populous countries of the world, and has a population growth rate of around $2 \%{ }^{4}$, it also has high rate of infertility (21.9\%); 3.5\% primary and $18.4 \%$ secondary the prevalence of infertility in Pakistan is $21.9 \% 5$.

Increasing prevalence of obesity in recent decades has been preceded by dramatic dietary changes in industrialized societies ${ }^{6}$. Over the past 100 years, there has been a considerable shift in the human diet, particularly with respect to the 
amount and type of consumed fat. High FSH levels strongly predict poor fertility in younger women compared to older women. A study reported that elevated basal day $3 \mathrm{FSH}$ level is strongly correlated with diminished ovarian reserve in women aged more than 35 years and is associated with poor pregnancy rate (6\% versus $42 \%$ ) after induction of ovulation 7 . This objective of this study was to finding the association of FSH and LH with secondary infertility in obese women presenting at different outpatient departments of DHQ hos-pital Sahiwal.

\section{METHODOLOGY}

The cross sectional study was conducted at District head quarter hospital Sahiwal, from March 2018 to May 2018 after approval from Institutional Review Board of Sahiwal Medical College Sahiwal. A validated questionnaire was filled by the patients after taking informed consent from them. Convenient sampling technique was used. Blood samples of the patients were also taken to calculate serum FSH and serum LH.

Sample size was calculated according to following formula:

$$
\text { Sample Size }=\frac{Z_{1-a / 2} 2 p(1-P)}{d^{2}}
$$

$\mathrm{Z} 1-\mathrm{a} / 2=$ is standard normal variant (at $5 \%$ type 1 error $(p<0.05)$ it is 1.96 . As in majority of studies

$p$-values are considered significant below 0.05 hence 1.96 is used in formula.

$p=$ Expected proportion in population based on previous studies or pilot studies $=0.20(7)$

$\mathrm{d}=$ Absolute error or precision $=0.08$

Sample size $=60$.

Convenient sampling technique was used. Blood samples of the study participants were taken and serum was separated by centrifugation. Commercially available enzyme-linked immunosorbent assay (ELISA) kits were used for biochemical estimation of serum follicle stimulating hormone (FSH) (Cat\# DKO010; Diametra), luteinizing hormone (LH) (Cat \# DKO009; Diametra).
The Data was assessed by IBM-SPSS version 24. Frequency distributions of study participants were calculated. Significance of the associations was assessed by independent sample t-test. Bivariate analysis was also done to check the effect of different factors on secondary infertility separately. The $p$-value $<0.05$ was taken as statistically significant.

\section{RESULTS}

Mean age of our study participants was 32.21 \pm 3.22 years. A total of $54(90 \%)$ out of 60 obese females were suffering from secondary infertility. Obesity status of the females was calculated by checking their basal metabolic index. Females with BMI more than 25 were obese. Mostly $(43.3 \%)$ belonged to middle class socioeconomic

Table-I: Frequency of demographic variables with percentages $(n=60)$.

\begin{tabular}{|c|c|c|}
\hline Variables & Frequency & Percentage \\
\hline \multicolumn{3}{|l|}{ Age Groups } \\
\hline $25-30$ & 21 & 35 \\
\hline $31-40$ & 39 & 65 \\
\hline \multicolumn{3}{|l|}{ Residence } \\
\hline Urban & 32 & 53.3 \\
\hline Rural & 28 & 46.7 \\
\hline \multicolumn{3}{|c|}{ Socioeconomic Group } \\
\hline Lower Class & 16 & 26.6 \\
\hline Middle Class & 26 & 43.3 \\
\hline Upper Class & 18 & 30.1 \\
\hline \multicolumn{3}{|c|}{ Secondary Infertility } \\
\hline Yes & 54 & 90 \\
\hline No & 6 & 10 \\
\hline
\end{tabular}

group. Nearly $54 \%$ were from urban residential areas. Majority belonged to $(65 \%)$ age group between 31 to 40 years (table-I).

When we calculated the association of serum FSH and serum LH with the secondary infertility in these study participants then it was conclusive to find out that mean levels of both FSH and LH were quite low $(12.11 \pm 1.14$ and $21.97 \pm 3.74$ respectively) in patients with secondary infertility as compared to those which were not suffering from it. Association of serum FSH was also found to be statistically significant with secondary infertility $(p=0.042)$. Though serum LH levels were not significantly associated (table-II). 
We also confirmed the role of FSH in causing secondary infertility in our study subjects by checking our data through bivariate analysis. It was again confirmed as serum FSH was again significantly associated with secondary infertility $(p=0.001)$ with odd's ratio of 0.117 . Other factors like serum LH levels, age, basal metabolic index and socio-economic status all were non-significant (table-III).

Table-II: Association of Serum Follicle Stimulating Hormone (FSH) and Serum Luteinizing Hormone (LH) with secondary infertility in obese women calculated by independent sample $t$-test $(n=60)$.

\begin{tabular}{l|c|c|c}
\hline \multirow{2}{*}{ Variable } & \multicolumn{2}{|c|}{ Secondary infertility } & \multirow{2}{p}{$\begin{array}{c}p- \\
\text { value }\end{array}$} \\
\cline { 2 - 3 } & Yes (n=54) & No (n=6) & \\
\hline $\begin{array}{l}\text { Mean Serum } \\
\text { FSH (ng/ml) }\end{array}$ & $12.12 \pm 1.14$ & $17.42 \pm 2.24$ & 0.042 \\
\hline $\begin{array}{l}\text { Mean Serum } \\
\text { LH (ng/ml) }\end{array}$ & $21.97 \pm 3.74$ & $68.87 \pm 1.66$ & 0.075 \\
\hline
\end{tabular}

Table-III: Bivariate Analysis of different variables related to infertility in obese women.

\begin{tabular}{l|c|c}
\hline Variables & Significance & $\begin{array}{c}\text { Odd's } \\
\text { Ratio }\end{array}$ \\
\hline Serum FSH & 0.001 & 0.117 \\
\hline Serum LH & 0.17 & 0.793 \\
\hline Age & 0.09 & 0.887 \\
\hline Basal Metabolic Index & 0.11 & 1.12 \\
\hline Socio-economic Status & 0.07 & 0.472 \\
\hline
\end{tabular}

\section{DISCUSSION}

Female patients with different gynecological related issues presented at gynecological outpatient department of DHQ Sahiwal and they were assessed after taking proper history and detailed examination. As found in previous study $^{8}$ most of our study participants were from urban population and middle socioeconomic group.

A previous study showed that the obese females tend to suffer more from gynecological disorders then the females withy normal BMI ${ }^{9}$. Another study showed 10 that levels of estrogen and FSH were found to be lower in females with secondary infertility but we did not calculate the serum estrogen levels due to limited budget. In another study ${ }^{11}$ they calculated the serum Estrogen, $\mathrm{FSH}, \mathrm{LH}$ and serum testosterone levels to have a comparison with infertility status but they checked for causes of primary infertility in contradiction to our study. An overwhelming of majority in our study population was suffering from secondary infertility $(90 \%)$ again in contradiction to previous study ${ }^{12}$ which found $65 \%$ of their study participants suffering from secondary infertility. Though our study participants presented to different hospitals with gynecological complains yet the secondary fertility was also found out in them.

Our study found out strong association between mean serum FSH levels with secondary infertility $(p=0.042)$. The mean levels of FSH were found out to be $12.12 \pm 1.14 \mathrm{ng} / \mathrm{ml}$ which were very low. All the participants also had menstrual irregularities so the levels of FSH were calculated independent of the day of menstrual cycle. A previous study also found strong association of FSH with obesity but not with secondary infertility status ${ }^{13,14}$. Patients without secondary infertility showed normal levels of serum FSH and higher than the females with secondary infertility. Tough the literature review ${ }^{15-17}$ proves that the low levels of serum FSH are good indicator for ovulation of the females and hence related to more chances of females with pregnancy yet our study showed that lower levels of FSH with menstrual irregularities are associated with secondary infertilities. But still other causes of menstrual irregularities should be sorted out.

Though our study failed to find significant association between serum LH levels and secondary infertility status yet the levels of LH were also lower $(21.97 \pm 3.74)$ in patients with secondary infertility as compared to those without secondary infertility $(68.87 \pm 1.66) \mathrm{ng} / \mathrm{ml}$.

We also did bivariate analysis of different factors which can cause the secondary infertilities in such females but it was astonishing to see that only serum FSH was found to be significantly associated $(p=0.001)$. A low odd's ratio of 0.117 also showed that these serum levels of $\mathrm{FSH}$ mainly caused the secondary infertility in our study population. Age, socio-economic status, 
serum LH levels and Basal metabolic index were non-significant. A previous study ${ }^{18}$ showed the mono variant analysis but they did not take the serum FSH and serum LH levels into the account.

\section{ACKNOWLEDGEMENT}

The authors are highly indebted to Dr. Sibgha Hashmi, Associate professor, Dept. of Gynecology, Sahiwal for her contributions and encouragement without which this study could not have been initiated.

\section{CONCLUSION}

Hence it is concluded that the low levels of serum FSH are strongly associated with secondary infertility in obese women. Our sample size was limited due to constrained budget but the study can be replicated in more participants with larger sample sizes in which more causes of secondary infertility should be sorted out.

\section{CONFLICT OF INTEREST}

This study has no conflict of interest to be declared by any author.

\section{REFERENCES}

1. Bilal M, Haseeb A, Rehman A. Relationship of polycystic ovarian syndrome with cardiovascular risk factors. Diabetes Metab Syndr 2018; 12(3): 375-80.

2. Al-Safi ZA, Liu H, Carlson NE, Chosich J, Harris M, Bradford $\mathrm{AP}$, et al. Omega-3 fatty acid supplementation lowers serum FSH in normal weight but not obese women. J Clin Endocr 2016; 101(1): 324-33.

3. Arain F, Arif N, Halepota H. Frequency and outcome of treatment in polycystic ovaries related infertility. Pak J Med Sci 2015; 31(3): 694.

4. Rehman R, Lalani S, Baig M, Nizami I, Rana Z, Gazzaz ZJ. Association between vitamin $\mathrm{D}$, reproductive hormones and sperm parameters in infertile male subjects. Front Endocrinol 2018; 9(1): 607 .

5. Zhaira D, Nafisa A, Ikram N. A mosaic of risk factors for female infertility in Pakistan. J Rawal Med Coll 2019; 23(2): 80-84.

6. Alam F, Khan TA, Amjad S, Rehman R. Association of oxidative stress with female infertility-A case control study. J Pak Med Assoc 2019; 69(5): 627.

7. Khodamoradi K, Parmar M, Khosravizadeh Z, Kuchakulla M, Manoharan M, Arora H. The role of leptin and obesity on male infertility. Curr Opinion Urol 2020; 30(3): 334-39.

8. Yilmaz FÇ, Sürücüoğlu MS, Çağiran FT. Association of obesity with primary and secondary infertility among infertile women in turkey: a cross-sectional study. J Food Nutri Res 2017; 5(4): 208-13.

9. Jawad AH, Ibrahim SA, Hadi DM, Jawad ZH. A Study of the correlation of some sex hormone with obesity in women with secondary infertility. Al-Nahrain J Sci 2015; 18(2): 44-49.

10. Owiredu WK, Ofori PN, Turpin CA, Obirikorang C, Acheampong E, Anto EO, et al. Weight management merits attention in women with infertility: a cross-sectional study on the association of anthropometric indices with hormonal imbalance in a Ghanaian population. BMC Res Notes 2019; 12(1): 545.

11. Suresh S, Vijayakumar T. Correlations of insulin resistance and serum testosterone levels with LH: FSH ratio and oxidative stress in women with functional ovarian hyperandrogenism. Indian J Clini Biochem 2015; 30(3): 345-50.

12. Sak $S$, Uyanikoglu $H$, Incebiyik $A$, Incebiyik $H$, Hilali NG, Sabuncu T, et al. Associations of serum fetuin-A and oxidative stress parameters with polycystic ovary syndrome. Clin Exp Reprod Med 2018; 45(3): 116.

13. Borght MV, Wyns C. Fertility and infertility: Definition and epidemiology. Clin Biochem 2018; 62(1): 2-10.

14. Chen X, Mo ML, Huang CY, Diao LH, Li GG, Li YY, et al. Association of serum autoantibodies with pregnancy outcome of patients undergoing first IVF/ICSI treatment: A prospective cohort study. J Reprod Immunol 2017; 122(1): 14-20.

15. Verma AK, Rajbhar S, Mishra J, Gupta M, Sharma M, Deshmukh G, et al. Anti-mullerian hormone: a marker of ovarian reserve and its association with polycystic ovarian syndrome. J Clin Diagn Res 2016; 10(12): QC10.

16. Sahin A, Urkmez A, Verit A, Yuksel OH, Verit FF. Psychologic and sexual dysfunction in primary and secondary infertile male patients. Arch Ital Urol Nefrol Androl 2017; 89(2): 120-24.

17. Kannan S, Srinivasan D, Raghupathy PB, Bhaskaran RS. Association between duration of obesity and severity of ovarian dysfunction in rat-cafeteria diet approach. J Nutrit Biochem 2019; 71(1): 132-43.

18. Kriseman M, Mills C, Kovanci E, Sangi-Haghpeykar H, Gibbons W. Antimullerian hormone levels are inversely associated with body mass index (BMI) in women with polycystic ovary syndrome. J Assis Reprod Genetics 2015; 32(9): 1313-16. 